
теплообмена и холодовой гиперреактивности дыхательных путей у больных бронхиальной астмой в сочетании с хроническим полипозным риносинуситом

Дальневосточный научный центр физиологии и патологии дыхания СО РАМН, Благовещенск

\title{
E.V.Zakharova
}

\section{Clinical and functional featuresof respiratory heat exchange and cold airway hyperresponsiveness in patients with bronchial asthma and chronic polypous rhinosinusitis}

\begin{abstract}
Summary
The aim of the study was to investigate airway conditioning function and cold hyperresponsiveness in patients with bronchial asthma (BA) and nasal polyps. One hundred and eleven asthma patients with or without chronic polypous rhinosinusitis (CPR) were examined. Respiratory heat exchange and cold airway hyperresponsiveness were assessed using thermometry of expired air during quiet breathing and isocapnic hyperventilation with cold air in comparison with a group of healthy persons. The conditioning nasal function was worsened in BA patients with CPRS. Disorders of nasal heat exchange led to decreased temperature of the exhaled air during quiet breathing and cold hyperventilation. These disorders were closely related to increased frequency and severity of cold airway hyperresponsiveness.

\section{Резюме}

Целью исследования было изучение особенностей кондиционирующей функции и холодовой реактивности дыхательных путей у больных бронхиальной астмой (БА) с полипами носа. Обследованы 111 больных БА без патологии верхних дыхательных путей и в сочетании с хроническим полипозным риносинуситом (ХПР). Проведена оценка респираторного теплообмена и холодовой гиперреактивности дыхательных путей по результатам термометрии выдыхаемого воздуха при спокойном дыхании и при изокапнической гипервентиляции холодным воздухом в сравнении с группой здоровых лиц. Обнаружено нарушение кондиционирующей функции носа у больных БА с ХПР. Расстройства теплообмена в носовой полости проявлялись снижением температуры выдыхаемого воздуха при спокойном дыхании через нос и при холодовой гипервентиляционной нагрузке. Нарушения респираторного теплообмена оказались тесно связаными с нарастанием частоты и степени выраженности холодовой гиперреактивности дыхательных путей.
\end{abstract}

Бронхиальная астма (БА), сочетающаяся с пролиферативной патологией верхних дыхательных путей, в первую очередь, с хроническим полипозным риносинуситом (ХПР), заслуживает особого внимания. Известно, что полипы носа усиливают проявления БА [1]. Сочетанные риносинуситы оказывают существенное влияние на характер течения БА [2].

В основе взаимодействия верхних и нижних дыхательных путей лежат нейрорефлекторные механизмы регуляции [3]. Давно известна роль носового сопротивления в формировании тонуса воздухоносных путей [4]. Этот фактор сохраняет свое значение и при охлаждении. Холодный воздух, сужая носовые ходы, увеличивает сопротивление потоку. Малая удельная теплоемкость и плотность воздуха дают возможность быстрых изменений его температуры в завихрениях и турбулентностях потока в верхних дыхательных путях [5]. Одновременно происходит увлажнение вдыхаемого воздуха за счет испарения влаги из слоя секрета, покрывающего респираторный тракт. В течение этого процесса дыхательные пути охлаждаются в результате конвекции и испарения. В какой мере эти процессы нарушаются при полипозном риносинусите у больных БА, остается неизвестным.
Цель настоящего исследования заключалась в изучении особенностей кондиционирующей функции и холодовой реактивности дыхательных путей у больных БА с сочетанным хроническим полипозным риносинуситом (ХПР).

\section{Материалы и методы}

Были обследованы 111 больных БА в возрасте от 18 до 53 лет с длительностью заболевания от 1 года до 27 лет. Для сравнительной характеристики изменений вентиляционной и кондиционирующей функций носа обследована также группа 26 здоровых добровольцев (10 мужчин и 16 женщин) в возрасте от 18 до 52 лет, у которых были измерены носовое сопротивление, температура выдыхаемого воздуха и изменения параметров поток-объем форсированного выдоха в ответ на изокапническую гипервентиляцию холодным воздухом (ИГХВ).

Для изучения клинико-функциональных особенностей течения БА с сопутствующим ХПР из общего количества больных были выделены 2 группы пациентов. В 1-ю группу (группу сравнения) вошли 25 больных БА без клинико-рентгенологических 
признаков патологии верхних дыхательных путей, во 2-ю - 86 больных БА с сопутствующим ХПР. Распределение больных по степени тяжести БА в группах было следующим: в 1-й группе - 4 (16 \%) пациента с интермиттирующим течением, 6 (24\%) с легким персистирующим течением, 15 (60\%) - со средней степенью тяжести; во 2-й группе - 11 (13\%), $19(22 \%)$ и 56 (65\%) больных соответственно. Достоверных различий в распределении пациентов по степени тяжести в обследуемых группах не было.

Холодовую бронхопровокационную пробу проводили с помощью устройства для охлаждения вдыхаемого воздуха. В течение 3 мин с заданным уровнем вентиляции (60\% от должной максимальной вентиляции легких) ингалировали охлажденную до $-20{ }^{\circ} \mathrm{C}$ воздушную смесь, содержашую $5 \% \mathrm{CO}_{2}$. До и после окончания пробы регистрировали параметры кривой поток-объем форсированного выдоха: объем форсированного выдоха за 1-ю с $\left(\mathrm{OФB}_{1}\right)$, пиковую объемную скорость выдоха (ПОС), мгновенные объемные скорости выдоха на уровне 50 и $75 \%$ жизненной емкости легких $\left(\mathrm{MOC}_{50}\right.$ и $\mathrm{MOC}_{75}$ соответственно). Проба считалась положительной, если сразу после ингаляции холодного воздуха ОФВ уменьшался более чем на $10 \%$ от исходного уровня.

Температуру вдыхаемого ( $\mathrm{t}^{\circ}$ вд. $)$ и выдыхаемого $\left(\mathrm{t}^{\circ}\right.$ выд.) воздуха регистрировали с помощью термодатчика МТ-57, вмонтированного в загубник и носовую маску.

\section{Результаты и обсуждение}

В табл. 1 представлены значения температуры воздуха при спокойном дыхании через нос у больных 1-й и 2-й групп в сравнении со здоровыми.

$\mathrm{t}_{\text {вд. }}^{\circ}$ соответствовала комнатной и достоверно не

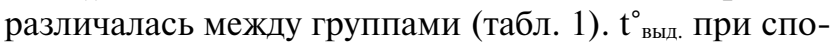
койном дыхании через нос у больных БА достоверно не отличалась от здоровых, в то время как наличие сопутствующего ХПР сопровождалось достоверным

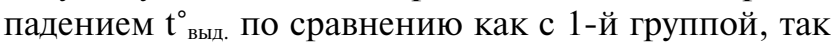
и с группой контроля. Разность $\mathrm{t}_{\text {вд. }}^{\circ}$ и $\mathrm{t}_{\text {выд. }}^{\circ}\left(\Delta \mathrm{t}^{\circ}\right)$ у больных с ХПР соответственно уменьшалась и достоверно отличалась от этого показателя у больных 1-й группы.

Таблица 1

Результаты пневмотермометрии при спокойном дыхании через нос $(M \pm m)$

\begin{tabular}{|c|c|c|c|}
\hline Показатель & Контрольная группа & 1 -я группа & 2 -я группа \\
\hline $\mathbf{t}_{\text {вд., }}^{\circ}{ }^{\circ} \mathrm{C}$ & $24,61 \pm 0,94$ & $24,32 \pm 0,76$ & $24,45 \pm 0,87$ \\
& & $p>0,05$ & $p>0,05$ \\
& & & $p_{1}>0,05$ \\
\hline $\mathbf{t}^{\circ}{ }_{\text {выд. }}{ }^{\circ} \mathrm{C}$ & $32,71 \pm 0,29$ & $32,94 \pm 0,35$ & $30,73 \pm 0,47$ \\
& & $p>0,05$ & $p<0,01$ \\
& & & $p_{1}<0,01$ \\
\hline $\mathbf{t}^{\circ},{ }^{\circ} \mathrm{C}$ & $8,10 \pm 0,69$ & $8,62 \pm 0,52$ & $6,28 \pm 0,54$ \\
& & $p>0,05$ & $p>0,05$ \\
& & & $p_{1}<0,05$
\end{tabular}

Примечание: $p$ - уровень значимости различий с контрольной группой, $p_{1}$ - с 1-й группой.
При дыхании через рот $\mathrm{t}_{\text {вд. }}^{\circ} \mathrm{t}^{\circ}$ выд. существенно не

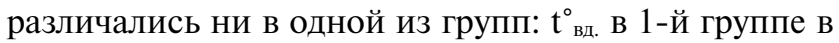
среднем составила $22,90 \pm 0,64{ }^{\circ} \mathrm{C}$, во 2-й $-23,14 \pm$ $0,87{ }^{\circ} \mathrm{C}$ (в контрольной группе $-23,06 \pm 0,76{ }^{\circ} \mathrm{C}$; $p>0,05), \mathrm{t}_{\text {выд. }}^{\circ}$ соответственно - 32,73 $\pm 0,21 ; 32,60 \pm$ 0,19 и $32,81 \pm 0,27^{\circ} \mathrm{C}(p>0,05)$.

По данным корреляционного анализа, у здоровых лиц обнаружена прямая линейная зависимость градиента температур выдыхаемого через нос воздуха с носовым сопротивлением потоку ( $r=0,54$; $p<0,05)$, а также с температурой тела $(r=0,79$; $p<0,01)$ и физическими характеристиками вдыхаемого воздуха - температурой $(r=0,69 ; p<0,05)$ и относительной влажностью $(r=0,60 ; p<0,05)$. Аналогичная зависимость установлена и при ротовом дыхании: $r$ градиента $\mathrm{t}_{\text {выд. }}^{\circ}$ бронхиальным сопротивлением составил $0,58(p<0,05), \mathrm{c} \mathrm{t}^{\circ}{ }_{\text {вд. }}-0,80(p<0,01)$ и с относительной влажностью $-0,60(p<0,05)$. При дыхании ртом исчезала зависимость $\mathrm{t}_{\text {выд. }}^{\circ}$ от температуры тела и максимальных скоростей потока на вдохе и выдохе при спокойном дыхании.

В 1-й группе при носовом дыхании тесная корреляция была обнаружена между $\Delta \mathrm{t}^{\circ}$ и величиной носового сопротивления $(r=0,67 ; p<0,01)$, исчезавшая при наличии сопутствующего ХПР (во 2-й группе $-r=0,29 ; p>0,05)$. Для получения максимальной термической нагрузки у 18 больных 1-й группы и 42 - 2-й группы выполняли пробу с ИГХВ. Уровень вентиляции при проведении пробы в группе здоровых был в среднем 72,5 \pm 9,0 л/мин, что составило 103,2 \pm 9,3\% от заданной минутной вентиляции, в 1-й группе - 53,3 \pm 6,1 л/мин (74,8 \pm 4,1 \%), во 2-й - 52,4 \pm 5,3 л/мин $(70,4 \pm 6,7 \%)$. Никто из больных не смог адекватно выдержать требуемую вентиляционную нагрузку.

По результатам пневмотермометрии (табл. 2), $\mathrm{t}_{\text {выд. }}^{\circ}$ в конце ИГХВ у больных 2-й группы в среднем была достоверно ниже, чем в 1-й группе.

На рис. 1 показаны кривые изменения $\mathrm{t}^{\circ}$ выд. в ходе выполнения пробы ИГХВ. На всем ее протяжении

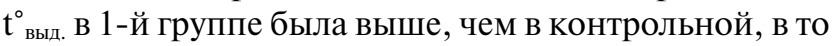
время как во 2-й группе она была систематически ниже, начиная с 50-й пробы.

Таблица 2

Параметры респираторного теплообмена при ИГХВ

\begin{tabular}{|c|c|c|c|}
\hline Показатель & $\begin{array}{c}\text { Контрольная группа } \\
(n=26)\end{array}$ & $\begin{array}{c}\text { 1-я группа } \\
(n=18)\end{array}$ & $\begin{array}{c}\text { 2-я группа } \\
(n=42)\end{array}$ \\
\hline $\mathrm{t}_{\mathrm{BA} .}^{\circ},{ }^{\circ} \mathrm{C}$ & $-18,47 \pm 0,35$ & $\begin{array}{c}-18,21 \pm 0,51 \\
p>0,05\end{array}$ & $\begin{array}{c}-18,64 \pm 0,60 \\
p>0,05 \\
p_{1}>0,05\end{array}$ \\
\hline$\Delta \mathbf{t}_{\text {выд. }}^{\circ}{ }^{\circ} \mathbf{C}$ & $3,96 \pm 0,36$ & $\begin{array}{c}4,29 \pm 0,59 \\
p>0,05\end{array}$ & $\begin{array}{c}4,28 \pm 0,43 \\
p>0,05 \\
p_{1}>0,05\end{array}$ \\
\hline $\mathrm{t}_{\text {кон., }}^{\circ} \mathrm{C}$ & $28,16 \pm 0,65$ & $\begin{array}{c}28,61 \pm 0,31 \\
p>0,05\end{array}$ & $\begin{array}{c}27,42 \pm 0,35 \\
p>0,05 \\
p_{1}<0,05\end{array}$ \\
\hline
\end{tabular}

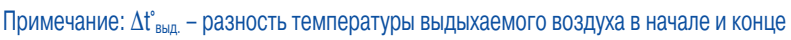
ИГХВ; $t_{\text {кон. }}^{\circ}$ - температура выдыхаемого воздуха в конце ИГХВ; $p$ - уровень значимости различий в сравнении с контрольной группой, $p_{1}-c 1$-й группой. 


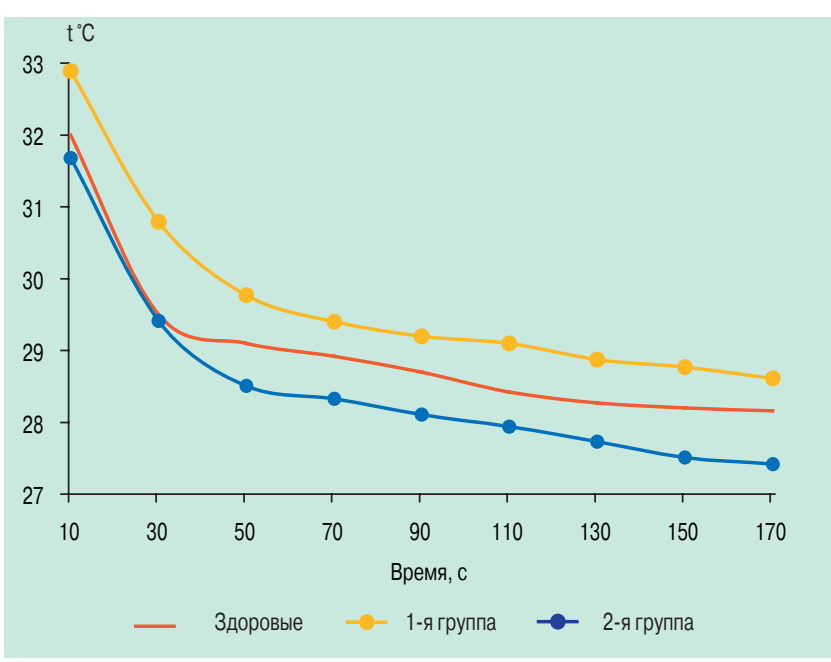

Рисунок. Динамика $\mathrm{t}_{\text {выд. }}^{\circ}$ на протяжении ИГХВ

Клинические проявления раздражения дыхательных путей после холодовой бронхопровокации в виде приступообразного кашля различной интенсивности, затруднения дыхания отмечались у 11 (61\%) больных 1-й группы и 32 (76 \%) - 2-й группы (из 18 и 42 протестированных соответственно). При индивидуальной оценке данных ИГХВ диагностически значимое падение ОФВ 1 имелось у 15 больных 1-й группы и $38-2$-й группы $\left(\chi^{2}=0,123 ; p>0,05\right)$.

Характер реакции дыхательных путей на ИГХВ в обеих группах был однонаправленным и характеризовался ухудшением бронхиальной проходимости, хотя степень данного ухудшения различалась (табл. 3). У больных 2-й группы отмечалось достоверно большее снижение $\mathrm{OФB}_{1}$ и MOC $_{50}$ спустя 1 мин после окончания холодовой бронхопровокационной пробы, чем у больных 1-й группы, что свидетельствовало о более выраженной холодовой гиперреактивности дыхательных путей. Через 5 мин после провокации большая степень падения указанных параметров в группе больных с ХПР сохранялась, хотя и не достигала статистически достоверных различий с 1-й группой.

У больных БА без сопутствующего ХПР, как и в контрольной группе, зависимости между температурой выдыхаемого воздуха и степенью последующей обструкции дыхательных путей не было обнаружено. В группе больных БА с сочетанным ХПР установлена высокая степень прямой корреляции между конечной температурой выдыхаемого воздуха и падением ОФВ 1 после бронхопровокации $(r=0,63$; $p<0,01)$, что указывает на роль нарушений кондиционирования воздуха в формировании холодовой гиперреактивности дыхательных путей при БА с сопутствующим ХПР.

У больных БА без ХПР исходная величина $\mathrm{MOC}_{75}$ тесно коррелировала со степенью ее падения после холодовой бронхопровокации $(r=-0,43 ; p<0,01)$. В группе больных БА с сопутствующим ХПР степень падения ОФВ 1 сразу после пробы зависела от величины носового сопротивления и температуры выдыхаемого через нос воздуха при спокойном дыхании: соответственно $r=-0,43(p<0,05)$ и $r=0,37(p<0,05)$.
При индивидуальной оценке полученных данных измененная реактивность дыхательных путей на воздействие холодным воздухом, верифицированная по данным ИГХВ, выявлена у 15 (83 \%) больных 1-й группы и у 39 (93\%) - 2-й группы.

Таким образом, в результате проведенного исследования обнаружено нарушение кондиционирующей функции носа у больных БА с ХПР. Расстройства теплообмена в носовой полости проявлялись

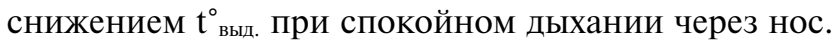
Если в 1-й группе больных БА была обнаружена тесная корреляция между $\Delta \mathrm{t}^{\circ}$ при носовом дыхании и величиной носового сопротивления ( $r=0,67$; $p<0,01)$, то при наличии сопутствующего ХПР она исчезала $(r=0,29-$ во 2-й группе; $p>0,05)$. Это означает, что нарушение теплообмена в носовой полости при ХПР связано с тем, что при формировании полипов значительно снижается теплопроводность слизистой оболочки в связи с ее утолщением, отеком, уменьшением степени васкуляризации.

Использование пробы с ИГХВ через рот позволило выявить скрытые нарушения кондиционирующей функции и нижних дыхательных путей. Так,

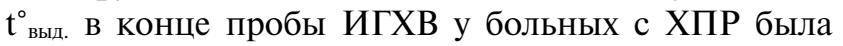
достоверно ниже, чем у больных БА без ХПР. По данным литературы известно, что для БА, в отличие от хронического бронхита, не характерно нарушение кондиционирующей функции дыхательных путей в связи с особенностями персистирующего

Таблица 3

Реакция дыхательных путей на ИГХВ (\% от исходной величины)

\begin{tabular}{|c|c|c|c|}
\hline Показатель & Контрольная группа & 1-я группа & 2-я группа \\
\hline \multirow[t]{3}{*}{$\triangle П О С$ через 1 мин } & $1,0 \pm 2,3$ & $-22,3 \pm 4,0$ & $-24,7 \pm 3,7$ \\
\hline & & $p<0,001$ & $p<0,001$ \\
\hline & & & $p_{1}>0,05$ \\
\hline \multirow[t]{3}{*}{$\triangle \Pi О С$ через 5 мин } & $-2,9 \pm 2,2$ & $-22,1 \pm 3,6$ & $-26,3 \pm 3,3$ \\
\hline & & $p<0,001$ & $p<0,001$ \\
\hline & & & $p_{1}>0,05$ \\
\hline \multirow[t]{3}{*}{$\triangle 0 Ф B_{1}$ через 1 мин } & $-2,7 \pm 1,5$ & $-17,3 \pm 2,1$ & $-24,3 \pm 2,4$ \\
\hline & & $p<0,001$ & $p<0,001$ \\
\hline & & & $p_{1}<0,05$ \\
\hline \multirow[t]{3}{*}{$\triangle 0 Ф B_{1}$ через 5 мин } & $-4,4 \pm 1,8$ & $-17,1 \pm 2,3$ & $-22,3 \pm 2,4$ \\
\hline & & $p<0,01$ & $p<0,001$ \\
\hline & & & $p_{1}>0,05$ \\
\hline \multirow[t]{3}{*}{$\triangle \mathrm{MOC}_{50}$ через 1 мин } & $-9,7 \pm 3,6$ & $-25,7 \pm 3,4$ & $-38,3 \pm 3,6$ \\
\hline & & $p<0,05$ & $p<0,001$ \\
\hline & & & $p_{1}<0,05$ \\
\hline \multirow[t]{3}{*}{$\triangle \mathrm{MOC}_{50}$ через 5 мин } & $-3,5 \pm 4,2$ & $-26,1 \pm 4,4$ & $-37,4 \pm 4,0$ \\
\hline & & $p<0,01$ & $p<0,001$ \\
\hline & & & $p_{1}>0,05$ \\
\hline \multirow[t]{3}{*}{$\triangle \mathrm{MOC}_{75}$ через 1 мин } & $-3,6 \pm 5,1$ & $-27,4 \pm 3,9$ & $-35,2 \pm 3,8$ \\
\hline & & $p<0,001$ & $p<0,001$ \\
\hline & & & $p_{1}>0,05$ \\
\hline \multirow[t]{3}{*}{$\triangle \mathrm{MOC}_{75}$ через 5 мин } & $-2,1 \pm 6,7$ & $-26,8 \pm 4,8$ & $-36,0 \pm 4,2$ \\
\hline & & $p<0,01$ & $p<0,001$ \\
\hline & & & $p_{1}>0,05$ \\
\hline
\end{tabular}

Примечание: $p$ - уровень значимости различий в сравнении с контрольной группой, $p_{1}-$ с 1-й группой. 
воспаления [6]. Последнее сопровождается повышенной васкуляризацией слизистой оболочки дыхательных путей и некоторым усилением респираторного теплообмена. Действительно, в проведенных

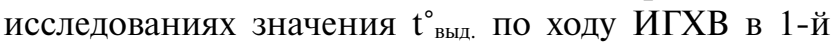
группе были систематически выше, чем у здоровых людей. В то же время у пациентов с ХПР они приближались к значениям, установленным у больных хроническим бронхитом [6]. Это свидетельствовало о том, что и в трахеобронхиальном дереве у больных БА при сопутствующем ХПР ускоряются процессы ремоделирования, приводящие к снижению кондиционирующих способностей дыхательных путей.

Нарушения респираторного теплообмена у больных БА с ХПР оказались тесно связаны с холодовой гиперреактивностью дыхательных путей. Как известно, измененная бронхиальная реактивность на вдыхание холодного воздуха весьма характерна для больных БА [6]. Она проявляется совокупностью клинических симптомов, основными из которых являются затруднение дыхания, удушье, кашель. Полученные данные свидетельствуют, что при присоединении ХПР частота и степень выраженности холодовой гиперреактивности дыхательных путей нарастает. Меняется и симптоматика ее проявлений в сторону увеличения частоты признаков дисфункции носа.

\section{Заключение}

Таким образом, течение БА, сочетающейся с ХПР, характеризуется формированием нарушений конди- ционирующей функции и проходимости носа, скрытыми нарушениями респираторного теплообмена в нижележащих дыхательных путях, а также связанным с ними усилением холодовой гиперреактивности дыхательных путей.

\section{Литература}

1. Global Initiative for Asthma: Global strategy for asthma management and prevention: Revised 2006. Available at: www.ginasthma.org

2. Dursun A.B., Sin B.A., Dursun E. et al. Clinical aspects of the link between chronic sinonasal diseases and asthma. Allergy Asthma Proc. 2006; 27: 510-515.

3. Буков В.А., Фельбербаум Р.А. Рефлекторные влияния с верхних дыхательных путей. М.: Медицина; 1980.

4. Плужников М.С. Рязанцев С.В. Роль верхних дыхательных путей в физиологии и патологии бронхолегочной системы. В кн.: Путов Н.В. (ред.). Болезни органов дыхания: Руководство для врачей. М.: Медицина; 1989; т. 1: $101-112$.

5. Proctor D.F., Andersen J. The nose: upper airway physiology and the atmospheric environment. Amsterdam: Elsevier Biomedical Press; 1982.

6. Приходько А.Г., Перельман Ю.М. Клинико-функциональная характеристика холодовой гиперреактивности дыхательных путей при хронических болезнях органов дыхания. В кн.: XVI Национальный конгресс по болезням органов дыхания. II Конгресс Евроазиатского респираторного общества, С.-Петербург, 14-17 нояб. 2006 г.: Сборник трудов конгресса. СПб.; 2006. 56.

Поступила 12.09.08 () Захарова Э.В., 2008

удк [616.248-06:616.24-002.2]-092 